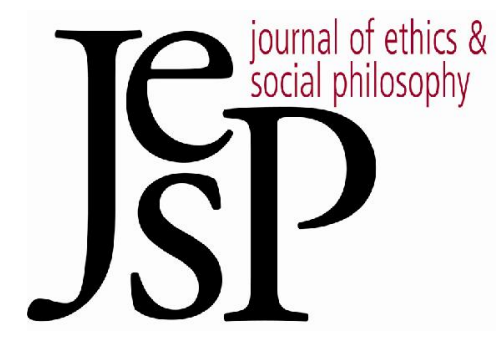

\title{
INSTRUMENTAL RATIONALITY: NOT DEAD YET
}

BY DAVID SOBEL

Journal of Ethics\& Social Philosophy

SYMPOSIUM I| DECEMBER 2005

URL: WWW.JESP.ORG

COPYRIGHT @ DAVID SOBEL 2005 


\title{
INSTRUMENTAL RATIONALITY: NOT DEAD YET ${ }^{1}$
}

\author{
By D avid Sobel
}

\begin{abstract}
N THIS PAPER I WILL LARGELY confine myself to trying to understand and criticize the final section of Joseph Raz's "The Myth of Instrumental Rationality." 2 This section, entitled "The Myth of Instrumental Rationality," generates the most exciting conclusions of Raz's paper. My paper will have two parts. In the first part, I attempt to understand how the final part of Raz's paper fits into the rest of the paper and to assess his arguments for his stated conclusions. There I aim to critique the argumentative structure of the paper as Raz describes it. In the second part, I offer a looser interpretation of his central concerns. ${ }^{3}$ This looser interpretation is motivated by what I see as the force of my criticisms in the first part and by an attempt to understand some aspects of his text which seem somewhat puzzling on the strict interpretation. I will be tentatively suggesting some changes in strategy or emphasis from the presentation in his paper. There is quite a lot going on in Raz's dense and thoughtful paper, and I am unfortunately forced to skip over much of it.
\end{abstract}

\section{Part 1}

Using a broad brush, Raz's positive story (ignoring his critique of other views) up to section five involves a distinction between two different kinds of normative standards - those that flow from the "facilitative principle" and those that flow from the notion of a "well functioning deliberative process." The former asserts that one has reason to bring about that which is valuable. Suppose it is valuable to appreciate Peruvian flute music. The facilitative principle claims I have reason to appreciate such music even if I do not know that it is valuable (assuming I am capable of appreciating it) and even if I do not know how to go about getting some to listen to (assuming that it is nonetheless possible for me to do so). The facilitative principle is unaltered by our lack of knowledge of the good or our ignorance about how to achieve the good. A virtue of this story is that people who disagree about what makes something valuable can agree that they each need a notion of this sort. That is, a notion of what would constitute the right answer for an agent to hit on,

\footnotetext{
1 I am grateful to Steve Wall for several very helpful discussions that improved this paper. I presented an early version of this paper in response to Raz at The University of Maryland Conference on Practical Rationality. I am grateful to the audience there for helpful discussion and to Raz for his feedback. I am also grateful to the editors of this journal for helpful advice in making this paper better.
}

2 Joumal of Ethics and Social Philosphy, Vol. 1, No. 1, April 2005. All in-text references refer to this work. 
abstracting away from epistemic limitations of the agent. Such a notion allows us to mark the thought that there is a right answer to our deliberative questions that we might fail to hit on. If adopting an end automatically gave one practical reason to get what one was aiming at, then there would be a sense in which one could not fail to hit on the right answer in practical deliberation - that is, we could not adopt as an end something that we had no reason to. We must avoid a kind of automatic vindication of every practical decision we make, while allowing that adopting ends does have a normative upshot in the way that Raz insists. Many subjectivists about practical reason, for example, aim to provide an account of this sort and so radically idealize the information available to the deliberator. The facilitative principle, I believe on Raz's view, exhausts the story of our practical reasons. Reasons, in this sense, arise only in response to the genuinely valuable.

The other source of normativity, as they say, is a matter of wellfunctioning processing of our deliberative and executive rational capacities. Whatever else is true of this category, it is needed to help us understand several different kinds of practical normative mistakes that the facilitative principle does not ground. For example, consider the person who believes that the thing she thinks valuable is to be found at $A$ and the valueless thing at $B$ (when in fact the reverse is the case). Such a person makes a kind of normative mistake if she, through insufficient attention to her own beliefs, shows up where she believes B is. Such a person has not heeded her facilitative reasons, although perhaps she has luckily acted in accord with them. But independently of that story, Raz agrees, there is an intrinsic practical normative defect in this person. A similar sort of defect is found in the person who mistakenly thinks $\mathrm{A}$ is worth pursuing and $\mathrm{B}$ is not, but who fails to take measures to bring about $\mathrm{A}$ and instead takes measures to bring about B. Raz is saying, rightly in my view, that this person makes a normative mistake that is quite independent of the goodness or badness of the upshot of their action (after all, as Raz notes, for unforeseeable reasons the upshot might be the production of more, rather than less, goodness - perhaps even, in some cases, reliably so). Thus we can criticize the above agent as making a mistake even without knowing if she is right or wrong about what has value.

I find all of this not only lucid, but compelling. I even like Raz's terminology of limiting practical "reasons" to the former story and limiting the notion of practical "rationality" to the latter epistemically laden story.

But I find it much harder to understand what is going on in section five ("The Myth of Instrumental Rationality"). The first thing I find confusing is why Raz thinks the above story is so odd. He tells us up front in section five that he will confront the "strangeness of the view I am defending" [23] and, earlier, he warns of the "oddity of my conclusions." [3] Raz seems to think the above story that distinguishes the facilitative principle from proper functioning is odd because the two stories are independent of each other. Raz does not explicitly say what he finds so odd about the above story. In his most helpful words on this topic, he points to the "wedge" he has drawn be- 
tween reasons and rationality and asks "What explains this divide between facilitative reasons and instrumental rationality?" [24] My best guess is that Raz finds it odd that there should be these two separate stories and that neither story should be subsumable under the other. But is this odd? Consider how things are in theoretical matters. In one sense, the truth sets the standard for success in belief in something like the way that value sets the standard with respect to action. But there is also an epistemically relativized standard which carries normative force. We should, in this sense, believe what the best evidence that we can gather supports. And we fail to live up to this normative standard even if our belief in fact hits on the truth.

This does not seem odd to me. There are facts that set a normative standard for what to believe, but which can be epistemically unavailable. Clearly, then, in one sense one ought to believe what is true and, in another sense, one ought to believe what is justified given what evidence one has. This is just the upshot of our good deliberation not always having the power to discern the true answer, but good deliberation carrying normative force anyway.

But I also do not understand how his main reaction to this is supposed to help. He says the "answer" to the above question about what explains the divide between the two sources of normativity is that "instrumental rationality" is not a "distinctive form of rationality or of normativity." [24] I can only see this as an answer that alleviates the puzzlement Raz feels in the face of the divide if it makes the divide more intelligible or if it dissolves the divide. But I don't see that it does either or even that Raz claims that it does either.

How is Raz's claim that instrumental rationality is not distinct supposed to alleviate whatever oddness he finds in the divide between reasons and rationality? The simplest answer would be if the lack of distinctiveness of instrumental rationality showed us that there was no real grand divide between reasons and rationality of the sort that Raz previously had argued for. Raz could be clearer about all this, but I do not think this is his view. I think he thinks the reasons/ rationality divide is real and merely claims that instrumental rationality is not a distinct kind of rationality. But, if so, how does that help alleviate the oddness of the view that Raz had talked himself into by the end of section four? I am afraid I have no answer and I do not see where Raz takes himself to offer an answer.

But even if there were no answer, one might say that this matters very little. For, one might say, Raz's main point is that there is nothing worth calling instrumental rationality, and his arguments for this conclusion could be good even if they do not dispel whatever oddness Raz saw in his earlier conclusions. Let us turn to this more important topic. Raz tells us that he will "confine the term 'instrumental irrationality' to the malfunctioning of our capacity to react properly to perceived reasons that manifests itself in failure to pursue available means to our ends." [15] As Raz here uses the term, claims about whether or not a person has it as her end to $\mathrm{X}$ is a descriptive, 
not normative, claim. Ends, in this sense, are not necessarily good or proper things to aim at.

Raz's thesis is that there is "no disindiveform of rationality or normativity that merits the name instrumental rationality. In particular, there is no specific form of rationality or normativity that concerns the relations between means and ends." [24] To properly understand this thesis, one must hear the emphasis that Raz has put on the word "distinctive" in the above claim. His central claim here is that there is no general kind of normative mistake that we make in all and only cases in which we fail to take the acknowledged best means to our adopted ends.

He is not claiming that we make no mistake in such cases. Rather, the mistake we make there is of a more general kind that can occur in other contexts. Raz's central problem with the notion of instrumental rationality is that it does not cut normativity at the joints. The idea seems to be that for there to be such a thing as instrumental rationality, there must be a kind of mistake that is unique to cases in which we fail to take the acknowledged best means to our adopted ends. Raz holds that, because there is no unique mistake that holds in such cases, instrumental rationality is a myth and that "there is no such thing as instrumental irrationality" [26].

Raz offers two cases designed to show that the same sort of mistake that takes place when we fail to take the acknowledged best means to our adopted ends can occur in other contexts. First, he tells us: "Weakness of the will is not confined to cases where we fail to take the means to our ends [...]. Weakness of the will can make us fail to adopt ends that we know (or believe we do) that we should adopt." [26] Second, "chronic dithering may make me miss the opportunity to realize my ends. But clearly chronic dithering and indecision may also make me fail to adopt ends that I am in a position to know that I should adopt. [... ] Again, the source of the failure is the same, regardless of whether it affects choice of ends or of means." [26]

Much will hang here on exactly what we mean by saying that an agent has it as her end to do something. But Raz's examples point to cases where it seems that the agent recommends to herself to make it her end to do X but has so far not managed to do so. I do think there is a good point to maintaining that there is space between recommending to oneself that one make something an end and actually making it one of one's ends. Ends that I have managed to adopt will structure my life more than ends that I merely recommend adopting, even if only by causing regret at failing to live up to them. Marking the precise distinction between recommending that I make X my end and actually doing so is beyond the scope of this paper. But I am allowing that there is the sort of conceptual space that Raz is exploiting in these examples.

What is less clear to me is if his examples thereby count as cases in which the problem is not a failure of the agent to take the means to her ends. We might say that the agent has other ends which the failure to adopt ends in accord with her recommendation thwarts. In one of Raz's examples, he tells 
us: "My dithering may make me miss the opportunity to realize my ends. But clearly chronic dithering and indecision may also make me fail to adopt ends that I am in a position to know that I should adopt." [26] And the point of the example is to show that the sort of mistake involved in failures to take the means to one's end can also occur in cases in which one is not failing to take the means to one's ends. But if this is the point of the examples, Raz should be curious if failing to adopt ends one knows or believes (Raz is incautious between these two formulations) one ought to adopt itself is an example of failing to take the means to one's ends. Imagine someone with the end of adopting ends according to her own recommendations or with the end of not wasting time. Failing to adopt ends could itself thwart ends that one has.4

Raz seems to want cases where it is clear that the agent's failure to adopt an end counts as 1) a normative error and 2) a mistake by the agent's own lights, but 3) a case in which the agent has no ends which the mistake helps to thwart. It is not clear that the examples he provides are examples that have all these features. He will have to say more to persuade us that there are cases of the form he needs.

But let us grant that Raz's examples are examples of what he thinks they are. I still think Raz is hasty in saying that because the same mistakes we make in failing to take the means to our ends are also made when we fail to adopt the ends that we think we ought to adopt, therefore "there is no such thing as instrumental irrationality." [26]

A different, less dramatic, conclusion one might have reached is that instrumental rationality covers cases not only in which the relations between ends and means are in play, but also cases in which we fail or succeed in heeding our recommendations about what ends we ought to adopt. Call such a view "broad" instrumental rationality. Raz does not investigate the merits of such less dramatic options or discuss reasons to think that such views could not merit being called "instrumental rationality."

We might think that "broad" instrumental rationality is part of a still broader normative kind. For we might want to agree with Raz's highly intuitive and attractive thought that "we also feel that failure to take the means to one's ends is a distinct kind of failure, different from the failure to have proper ends, or to value them properly." [2] This latter kind of failure is "indifferent to the character of the ends." [3] Thus we might say that broader instrumental rationality collects the kinds of processing mistakes we make but ignores the fact that our ends or recommendations do or do not match up with what is genuinely valuable.

As I understand Raz, "broad" and "broader" instrumental rationality belong to the set of views he means to rule out on the grounds that they are not distinct. Raz claims that "there is no distinctive set of deliberative standards

4 David Schmidtz, “Choosing Ends," Ethics 104 (1994): 226-251, has a good discussion of this. 
that are involved in getting us to reason correctly from ends we have to means, and that are different from those that are involved in reasoning about which ends to have." [26] I hear this to claim that the kinds of mistakes involved in failing to respond well to one's own view of what has value are also involved when we fail to discern well what has genuine value and what does not. I think Raz sees this as one of the central conclusions of his paper.

But perhaps Raz does not mean to rule out "broad" and "broader" notions of instrumental rationality. Perhaps his point is really just specific to the case of means/ end failures. But if so, then, for me, Raz's thesis is drained of much of its interest. In any case, as I think Raz is after a broader claim, and as I think such a claim would be more interesting, I will hereafter assume he is seeking the broader claim - the one that aims to rule out "broad" and "broader" notions of instrumental rationality.

Given this, Raz's examples that I discussed above seem irrelevant to his conclusion. For these are cases in which it is assumed that the authoritative voice of the agent recommends one thing but the agent does another and that this is the mistake that need not involve means/ end failures. But if Raz is seeking to undermine "broader" instrumental rationality, he will have to show us more than that cases in which an agent does not take her own advice need not amount to failures of the means/ end kind. For now the question is if there is a distinct error involved in failing to take one's own advice that is independent of failing to generally respond well to what has value.

Should we generally say that there is no such thing as normative kind $X$ or that normative kind $\mathrm{X}$ is a myth when it is discovered that our intuitive understanding of the kind is not distinct in Raz's sense? That is, should we reject normative kind $\mathrm{X}$ when we learn that the same kind of mistakes that take place within its domain also can take place in other areas as well? Rather than rejecting normative kind $\mathrm{X}$ in such situations, we might see if there are any suitable expansions of the kind that cover the additional cases in which the same sort of mistake is made.

How should we then decide between rejecting normative kind $\mathrm{X}$ and adjusting our understanding of normative kind X? How should we decide between claiming that instrumental rationality is a myth and claiming that instrumental rationality has to do not only with the relationship between ends and means, but also with norms for moving from beliefs about what ends one should have to what ends one actually adopts?

Let us, for the sake of argument, assume that we have no further complaint against this broader notion of instrumental rationality other than that it arguably expands the concept beyond what it was previously thought to apply to. With that assumption in place, it seems clear to me how we should answer questions like this. We should choose the answer that seems less surprising and remarkable. For that will be a sign that we think that direction involves less conceptual revision. And if this were a sensible guide to how to proceed in such cases, then I think that expanding the concept of instrumental rationality in the ways I have discussed is less surprising and remarkable 
than rejecting the concept. To see this, notice that a paper with the title "Instrumental Rationality Also Covers Cases in Which One Recommends But Has Not Yet Adopted an End" would not have seemed quite so provocative.

Now it might be that Raz has views about what it would take to merit being called an account of instrumental rationality which rules out "broader" instrumental rationality as deserving the name. But, if so, he will have to tell us more about what it takes, in his view, to count as meriting that term and why the expanded concept could not rightfully inherit the mantle.

Raz holds that the central motivation for thinking that instrumental rationality is a "distinctive and particularly unproblematic form of rationality" [26] stems from varieties of the scientistic thought that it is "difficult to find a place for normativity" [27] in the world as science describes it. Raz holds that this general scientistic motivation has misled many into looking for an account that "explains away" normativity or renders normativity into unproblematic analytic truths about the relation between ends and means. I do not see why thinking "broader" instrumental rationality involves a distinctive kind of normative assessment, or thinking that this kind of assessment is especially unproblematic, need stem from anything like the scientism that Raz suggests.

"Broad" or "broader" instrumental rationality do seem to involve a distinctive and particularly unproblematic form of practical normative assessment. Consider first reasons to think it is distinctive. Shamelessly borrowing from Raz, I would want to say that failures to heed one's own authoritative voice involves an "executive" failure that failures to discern the valuable from the valueless need not involve. Roughly, these notions of rationality involve failures analogous to failures of validity rather than failures of soundness in reasoning since they involve maintaining an internal coherence in one's evaluative outlook or properly heeding one's own advice or, in any case, "executive" failures rather than "investigative" failures or problems with the accuracy of one's evaluative outlook. ${ }^{5}$

Raz responds to a view of this sort when he addresses the view of Wallace. Raz's primary complaint there is that failures of instrumental rationality are not made such by the undesirable nature of maintaining contradictions, but rather by a non-consequentialist assessment that the agent is "not functioning properly." Without speaking to Wallace's position, one could clearly hold that the problem with a manifest contradiction in one's attitudes, or a failure to listen to one's own advice, is not the undesirable upshot of such things but a more intrinsic assessment that to do these things is to be improperly functioning. Yet one could simultaneously think that this form of

5 On some Kantian views, this contrast (at least at the limit) will be held to be untenable. Standard subjectivist stories would hold that ideal information, as well as coherence, would be needed to collapse this distinction. Perhaps we could re-establish the distinction I want for the kind of Kantian I have in mind by noting the level of obviousness of the incoherence. 
improper functioning is distinctive from the sort that involves, for example, failures in detecting what is valuable.

Raz boldly asserts that "there is nothing wrong with holding contradictory beliefs as such." [20] He correctly points out that we may not know which belief is false and so have no reason to suspend one belief rather than the other. But this is not to the point if the issue is whether there is an intrinsic blemish in deliberation when one has contradictory attitudes and one's attitudes speak clearly about how best to resolve the contradiction. We only call a case an instance of weakness of the will when we not only have a contradiction between attitudes but also a clearly better and worse way of resolving the contradiction so as to restore internal coherence. He also points out that the pragmatic costs of suspending our beliefs may be too high to warrant doing so, which is clearly right. However, again, this is not to the point if the issue is not whether one has most reason overall to eliminate the contradiction, but rather whether it counts as an intrinsic blemish in one's deliberation to maintain a clear and obvious contradiction or failure to heed one's own advice.

Second, consider reasons to think that "broad" or "broader" instrumental rationality is "particularly unproblematic." Again an analogy with validity and soundness is helpful. Is there more or less agreement among experts about whether an argument is valid or sound? Obviously there is more agreement about whether an argument is valid. And this not only because soundness includes validity, but also because we agree more about whether an argument is valid than we agree about whether a premise is true. This point is largely duplicated when we switch to the practical domain where again we agree more about what one ought to do granted certain normative premises concerning what is worth pursuing than we tend to agree on such normative premises themselves. Thus, it is unsurprising and need not involve misguided scientistic motives to think that "broader" instrumental rationality would be less problematic than other normative aspects in the practical domain.

\section{Part 2 The Loose Reading}

Let's consider a different understanding of what is really at stake for Raz in this paper - one that perhaps strays from the text at times. I will offer suggestions of somewhat different ways to understand Raz's real concerns. I aim to helpfully develop paths that he might find tempting. However I do not mean to endorse these suggestions myself. I will be suggesting that it is not clear to me that Raz need claim that there is no such thing as instrumental rationality on route to his main points.

The facilitative principle holds that we have reason to take the means to achieving what is truly valuable. This is the domain of our reasons. Reasons are insensitive to our epistemic plight and to what we happen to adopt as our ends, since these things do not affect (or only rarely affect) what is truly valu- 
able or what is a means to what is truly valuable. Importantly, Raz is here treating the truth of the facilitative principle as a premise in his paper, a premise that he thinks we have very good reason to think true.

Raz maintains that the facilitative principle accounts for much of what people have wanted to account for with instrumental rationality, but not all. There is another class of normative recommendation and mistake. What's left over is the kind of normative recommendation associated with rationality. There is a kind of normative recommendation for the agent to take the means to what he thinks is worth pursuing or what he has adopted as his end, even if this belief is false or the end worthless. The normativity of this class, Raz maintains, cannot be explained indirectly via its (perhaps only longterm) usefulness in bringing us what is truly valuable. This is the domain of rationality.

For Raz, the central question then is how to account for this second kind of normativity. But in accounting for the normativity of this class, Raz seeks an account that recognizes and does not conflict with the truth of the facilitative principle. An account of rationality would conflict with the facilitative principle if, for example, it aspired to explain all of practical normativity without recourse to the facilitative principle.

Raz seems to want to account for the normativity of rationality. He seeks an account that 1) is in some sense continuous with the facilitative principle, 2) is anti-scientistic, implying that it is not motivated by the fear that value cannot find a comfortable home in a naturalistic world, and 3) is broad enough to encompass mistakes that do not occur merely between adopted ends and means. Raz also shows opposition to the idea that rationality should be seen as particularly unproblematic and more easily accounted for than the facilitative principle. We could now understand this to mean that he is especially resistant to explanations of rationality that have the ambition to be less ontologically freighted and to take over all the area of practical normativity - that is, to give us a way to live without the facilitative principle and its commitment to genuine values in the world. Raz need not fight the idea that rationality is less problematic than the facilitative principle in other ways.

If Raz dropped the claim that instrumental rationality is a myth, and instead put his points in terms of accounting for practical normativity in a way that complements and does not conflict with the facilitative principle, the view would look more compelling and would avoid the problems I mentioned in Part 1. The fight, as I see it, is not really about whether there is something worth calling instrumental rationality. The fight is about whether there is a satisfying account of rationality that can eliminate the need for the facilitative principle or whether the best account of rationality supplements and is continuous with the motivations for the facilitative principle. Thus the real issue is also whether the domain of practical normativity can be generally understood as a matter of being properly oriented toward value, whether actual or merely perceived. 
We might have guessed that the fate of instrumental rationality was not really central for Raz from his lack of energy for hunting down possible successors worthy of the mantle when the simplest version of instrumental rationality proved too simple. Additionally, had this really been important to him, he would have argued for "confining" the notion of instrumental rationality to the means/ ends cases rather than treating this as a stipulation. Finally, I think we see that the fate of instrumental rationality is not central for Raz by the motivations that he attributes to those that seek to defend the existence of instrumental rationality. As mentioned, he attributes scientistic motivations and an uncomfortableness with genuine value fitting into a naturalist world. But off-hand there seems little connection between believing that instrumental rationality is not a myth and believing those other things. These motives point us to what Raz is centrally keen to argue against, and it is not best described as whether or not instrumental rationality is a myth.

Raz tells us that, on Wallace's view, the problem in cases of instrumental irrationality is that agents have inconsistent beliefs. I think Raz selects Wallace as a target because, among other reasons, Wallace suggests that the mistake does not involve an improper orientation toward what is valuable or what the agent thinks is valuable. A person who held that really there was nothing that was of value, and on this basis held that there was no distinctively practical normativity, could embrace Wallace's view of the normative mistake in this area. Such a person might try to explain away what looks like a distinctively practical kind of normativity by turning it into a form of theoretical mistake. And such a view would conflict with the truth of the facilitative principle. Raz says that he is "assuming that rationality has to do with the perception of what are or are taken to be normative reasons, and the response to them." [5] But I think in his discussion of Wallace and elsewhere, Raz is attempting to motivate such a view rather than merely assuming it. (I do not attribute any of the above-mentioned possible motivations for Wallace's account of the source of the problem in cases of irrationality to Wallace.)

Instead, Raz would like to account for the normativity of rationality by invoking a story that is analogous to the facilitative principle. And there is a quick story of this kind to tell. One might say that rationality is just the subjective shadow of the facilitative principle. Rationality requires that one treat what one thinks is valuable enough to serve as one's ends in a distinctive way. But this is not a significant departure from the facilitative story, for it is really just the subjective attempt to comply with it in fallible agents. Further, this understanding of rationality presupposes a complementary picture of value that our rationality aims to hit. It presupposes something like the facilitative principle. This story thus accounts for the practical normativity of rationality in a way that is satisfyingly unified with Raz's account of practical normativity more generally. And, so far as I can see, Raz need not claim that instrumental rationality is a myth to make out such a case. 
Let me briefly conclude by mentioning problems and unanswered questions for the loose interpretation. A key advantage of this view, as I see it, is it keeps in place the Razian thought that properly intelligible action is oriented toward value. We can understand what people are doing, on this story, as fallibly aiming at what they think is valuable enough to aim for. But the key test for whether the facilitative principle and the shadow of the facilitative principle can account for all of practical normativity comes from the case of a person who has adopted ends that he thinks are unworthy (as Raz allows is possible [11, note 14]). In this case it seems that there remains a practical normative mistake in the person who fails to take the means to his ends, even when that person thinks that his end is not worth having or not properly oriented toward value. You think it is crazy to go to the party, but you decide to do so anyway. If you are going to go to the party, you really should bring beer. But you forget to bring beer. Y ou have made a practical mistake involving a failure of executive powers but it is not clear your mistake is covered by the facilitative principle or its shadow, which is just the subjective attempt to bring about what one believes is valuable enough to be worthy of being one's end.

Another way of getting at this worry is to remind ourselves of Raz's opposition to the view that because animals lack reasons for their "ends," our adopted ends too need not be adopted for reasons. [28] Presumably, Raz means to say that our ends must be adopted for what appear to us to be reasons. But then it becomes difficult, in the cases under discussion, to understand what counts for the agent as the reasons she thinks she has for adopting her end when she herself sees her end as valueless.

Perhaps it will be said that adopting an end, even against one's own advice, involves treating it as if it were valuable, and thus that failures to effectively pursue what one is treating as valuable is covered, in a sense, by the subjective shadow of the facilitative principle.

An additional worry is that the facilitative principle and its shadow can conflict, as when the facilitative principle recommends, on instrumental grounds, adopting deliberation that conflicts with the shadow. It remains to be explained, it seems to me, what the source of the normativity of the shadow is in cases in which the facilitative principle speaks against it and how to understand the practical upshot of a conflict between what one has reason to do and what would be rational.

Finally, I want to point out that subjectivist accounts of reasons for action of the kind I favor should not be seen as a target of Raz's paper. I have argued elsewhere that subjectivism, the view that an agent's contingent concerns ground all of her practical reasons, is best seen as an account of what there is reason to do in Raz's sense, rather than an account of rationality in his sense. Hume and Williams ignore the distinction between false beliefs that affect one's motivations that are based on sloppy deliberation and such false beliefs based on sensible deliberation. Each can cause a person, on their views, to act contrary to reason. This shows that they are not attempting to 
develop a notion of rationality as Raz uses the term. ${ }^{6}$ Additionally, subjectivists such as Williams do not aspire to "explain away normativity" as Raz suggests, but to vindicate the view that some things are really valuable for an agent and therefore give her distinctively practical reasons.

D avid Sobel

Department of Philosophy

Bowling G reen State University

david sobel@ hotmail.com

6 This is surely too quick to be convincing. I make this case more fully in "Subjective Accounts of Reasons for Action," Ethics 111, (April 2001): 461-92. 